\title{
MODAL INVERSION BY USING PARAMETERIZATION WITH CHEBYSHEV POLYNOMIALS
}

\author{
Fernando de Oliveira Marin ${ }^{1}$, Orlando Camargo Rodríguez², \\ Luiz Gallisa Guimarães ${ }^{3}$ and Carlos Eduardo Parente Ribeiro ${ }^{3}$
}

\begin{abstract}
This paper discusses the estimation of sound speed perturbations in a shallow water waveguide, from measurements of modal travel times. The formulation of the Inverse Problem is reduced to a least squares solution, being highlighted that the choice of discretization of the set of model parameters is of fundamental importance. In the Parameterization here discussed Chebyshev polynomials are considered, allowing to obtain satisfactory results. Finally, the original formulation is adapted to the case of unsynchronized arrivals.
\end{abstract}

Keywords: shallow water, tomography, orthogonal functions.

RESUMO. Este trabalho aborda a estimativa de perturbações de velocidade do som em um ambiente de águas rasas, a partir de medições de tempo de percurso modal. A formulação do Problema Inverso é reduzida a uma solução por mínimos quadrados, sendo destacado que a escolha da discretização do conjunto de parâmetros do modelo é de fundamental importância. Na parametrização aqui discutida são considerados polinômios de Chebyshev, os quais permitem obter resultados satisfatórios. Adicionalmente, a formulação original é adaptada ao caso de chegadas não sincronizadas.

Palavras-chave: águas rasas, tomografia, funções ortogonais.

\footnotetext{
${ }^{1}$ Instituto de Estudos do Mar Almirante Paulo Moreira (IEAPM), Divisão de Oceanografia Física, Rua Kioto, 253, Praia dos Anjos, 28930-000 Arraial do Cabo, RJ, Brazil. Phone: +55(22) 2622-9011/9073/9069 - E-mails: marin@marinha.mil.br; fernando.o.marin@gmail.com

2 Universidade do Algarve (UAlg), Departamento de Física, Faculdade de Ciências e Tecnologia (FCT), Campus de Gambelas, 8005-139, Faro, Portugal. Phone: +351289800 905, Ramal: 7633 - E-mail: orodrig@ualg.pt

3 Universidade Federal do Rio de Janeiro (UFRJ), Laboratório de Instrumentação Oceanográfica (LIOc), Centro de Tecnologia (CT), Bloco I, Sala 104e, Cidade Universitária, Illha do Fundão, 21941-611 Rio de Janeiro, RJ, Brazil. Phone: +55(21)3938-8852 - E-mails: lula@if.ufrj.br; parente@peno.coppe.ufrj.br
} 


\section{INTRODUCTION}

The lack of synoptic data (temperature, salinity, etc.) in coastal regions is an old problem. Indeed, the swiftness of the phenomena associated with shallow water, in combination with their respective small spatial scales, hinders proper sampling of the coastal ocean structure using conventional instruments. Such phenomena can have a major impact on regional oceanography, also affecting the performance of SONAR systems (Chiu et al., 1996). In this context, the Ocean Acoustic Tomography (OAT) arises as an important tool for monitoring environmental variabilities in shallow water regions. The OAT was originally designed for deep water regions, based on Ray Theory. However, tomographic methods based on Ray Theory are sometimes insufficient to shallow water regions, and alternatives have been found in the use of Matched Field Techniques and Modal Tomography (Taroudakis, 1994). This paper discusses the estimation of sound speed perturbation in a shallow water environment, from modal travel time measurements.

\section{THEORY}

\section{Modal Inversion}

The Normal Mode Theory is one of many methods used for the calculation of acoustic field in shallow water. The modal travel time tomography is based on the dispersive characteristics of the acoustic signal propagated. The effect of dispersion, very pronounced at low frequency, allows to obtain, from the modal group velocities, the corresponding travel times, which are different for each frequency. The Inverse Problem (from now on, IP) considered in the present work provides the sound speed perturbations $(\Delta \boldsymbol{c})$ from modal travel time perturbations $(\boldsymbol{\Delta} \boldsymbol{t})$. The starting point is the he homogeneous Helmholtz equation in cylindrical coordinates $(r, \phi, z)$, with cylindrical symmetry $(\partial / \partial \phi=0)$, expressed by

$$
\begin{aligned}
\nabla^{2} P(r, z) & +\frac{1}{\rho(z)} \nabla \rho(z) \cdot \nabla P(r, z) \\
& +k^{2}(r, z) P(r, z)=0
\end{aligned}
$$

where $P(r, z)$ is the acoustic pressure in the frequency domain, $\rho(z)$ the density (considered constant in each layer) and $k(r, z)$, the wavenumber. We can represent the solution of Eq. (1) at any range $r$ as a sum of $M$ local modes

$$
P(r, z)=\sum_{m=1}^{M}\left|H_{m}\right| e^{i \phi_{m}} u_{m}
$$

where $H_{m}$ is the modal amplitude, $\phi_{m}$, the modal phase and $u_{m}$, the modal eigenfunction. The Modal Phase, at range $R$, can be obtained by (Taroudakis, 1994)

$$
\phi_{m}=\int_{0}^{R} k_{m}(r) d r
$$

where $k_{m}(r)$ is the eigenvalue of order $m$, determined for each distance $r$, being associated with the depth equation (ordinary differential equation defined in $z$ ). The acoustic pressure, in the time domain, can be expressed as a linear combination of modes

$$
p(r, z, t)=\sum_{m=1}^{\infty} p_{m}(r, z, t),
$$

where each term, by the Fourier transform, can be expressed as

$$
p_{m}(r, z, t)=\int_{-\infty}^{+\infty}\left|H_{m}\right| e^{i\left(\phi_{m}-\omega t\right)} u_{m} d \omega
$$

From the condition of stationary phase $\left(\phi_{m}-\omega t=0\right)$, and by the definition of Modal Phase (Eq. 3), one can get the expression that relates the modal travel time to the modal phase

$$
t_{m}=\frac{\partial \phi_{m}}{\partial \omega} .
$$

The modal phase perturbation can be related to the wavenumber perturbation by the expression

$$
\delta \phi_{m}(r)=\int \delta k_{m}(r) d r
$$

with the wavenumber perturbation expressed by (Taroudakis, 1994)

$$
\delta k_{m}=\int_{0}^{\infty} Q_{m} \delta c d z
$$

where $Q_{m}$ is a function that depends on "reference" (unperturbed) environmental parameters

$$
Q_{m}=-\frac{\omega^{2}}{k_{m}} \frac{1}{\rho c^{3}} u_{m}^{2} .
$$

The modal travel time perturbation, at range $R$, can be expressed as

$$
\delta t_{m}=\int_{0}^{R} \int_{0}^{\infty} \frac{\partial Q_{m}}{\partial \omega} \delta c(r, z) d z d r .
$$

In a first approximation, for the Range-Independent (RI) case and depth of water column $D$, the Eq. (10) can be written as

$$
\delta t_{m}=R \int_{0}^{D} \frac{\partial Q_{m}}{\partial \omega} \delta c(z) d z .
$$




\section{Discretization}

We frequently seek to discretize the set of model parameters $(\boldsymbol{\delta} \boldsymbol{c})$, so that the IP can be solved by using the linear algebra methods. Discretizing the water column into a system with $L$ layers, i.e., $L+1$ depths, $z_{l}=\left[0, z_{2}, \ldots, z_{L+1}\right]$, as shown in the Figure 1, with $\Delta c_{l}$ corresponding to an average of $\delta c$ in the $l$ th layer, we can consider a matrix $\boldsymbol{\Delta} \boldsymbol{c}$ with $L$ elements $\Delta c_{l}$ (Rodríguez \& Jesus, 2000, 2002).

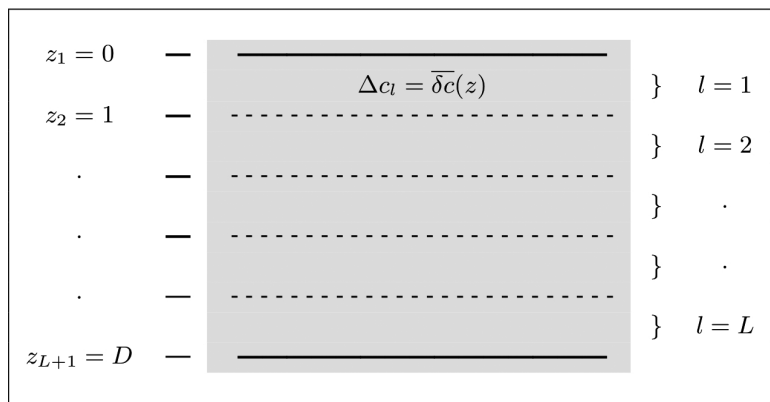

Figure 1 - Discretization of the water column in $L$ layers. Each $\Delta c_{l}$ corresponds to an average of $\delta c$ in the $l$ th layer.

Then, the Eq. (11) can be written as

$$
\delta t_{m}=\sum_{l=1}^{L} \overbrace{R \int_{z_{l}}^{z_{l+1}}\left(\frac{\partial Q_{m}}{\partial \omega}\right) \delta c d z .}^{(\mathrm{I})} .
$$

Making an approximation for the expression (I) of Eq. (12)

$$
R \int_{z_{l}}^{z_{l+1}}\left(\frac{\partial Q_{m}}{\partial \omega}\right) \delta c d z \approx \Delta c_{l} R \overbrace{\int_{z_{l}}^{z_{l+1}}\left(\frac{\partial Q_{m}}{\partial \omega}\right) d z,}^{\mathrm{G}_{m l}},
$$

the Eq. (12) can be reduced to a linear system

$$
\delta t_{m} \approx \sum_{l=1}^{L} \mathrm{G}_{m l} \Delta c_{l}, \quad m=1,2,3, \ldots, M,
$$

that leads to the matrix equation of the IP

$$
\mathrm{G} \Delta c=\delta t,
$$

relating a set of $M$ modal travel time perturbations $(\boldsymbol{\delta} \boldsymbol{t})$ to a set of $L$ average sound speed perturbations $(\boldsymbol{\Delta} \boldsymbol{c})$, through the operator $\mathrm{G}$. Then, $\boldsymbol{\Delta} \boldsymbol{c}$ is what we wish to determine. If $L<M$ (less layers than perturbations), the least squares solution is (Rodríguez \& Jesus, 2000, 2002)

$$
\Delta c=\left(\mathrm{G}^{\mathrm{T}} \mathrm{G}\right)^{-1} \mathrm{G}^{\mathrm{T}}(\delta t) .
$$

\section{Parameterization}

The goal of the parameterization is, as a general rule, reduce the degrees of freedom of the IP solution, in a controlled way. The formal expression of the parameterization is a linear combination of orthogonal basis functions. In general, sound speed perturbation can be expressed as an expansion in terms of orthogonal functions (Rodríguez et al., 1998; Rodríguez \& Jesus, 2002):

$$
\delta c=\sum_{i=1}^{I} \alpha_{i} F_{i}(z),
$$

where $\alpha_{i}$ is the expansion coefficient, and $F_{i}(z)$, the orthogonal function. The reason of the orthogonality condition is to guarantee $\alpha$ to be unique. Then, by the Eq. (17), the Eq. (12) can be written as

$$
\begin{aligned}
\delta t_{m} & =\sum_{i=1}^{I} \alpha_{i} \underbrace{\left[R \int_{0}^{D}\left(\frac{\partial Q_{m}}{\partial \omega}\right) F_{i}(z) d z\right]}_{\Gamma_{m i}} \\
& =\sum_{i=1}^{I} \alpha_{i} \Gamma_{m i},
\end{aligned}
$$

where $\boldsymbol{\Gamma}$ is a new matrix, whose elements $\Gamma_{m i}$ relate the modal travel time perturbations to the amplitudes of the orthonormal functions. Then, by the Eq. (18) one can get the matrix equation

$$
\Gamma \alpha=\delta t
$$

whose least squares solution $(L<M)$ is

$$
\alpha=\left(\Gamma^{\mathrm{T}} \Gamma\right)^{-1} \Gamma^{\mathrm{T}}(\delta t) .
$$

Several families of polynomials have the orthogonality property such as Legendre, Laguerre, Hermite e Chebyshev, among others. For the present work, we have chosen the Chebyshev polynomials of first kind, for its efficiency well reported in the literature, particularly due to the fast convergence of the resulting series.

\section{Parameterization with Chebyshev Polynomials}

Chebyshev polynomials are orthogonal functions which can be obtained recursively. As significant advantages of the representation of a function in terms of Chebyshev polynomials, we can highlight (Schultz \& Strayer, 2005, p. 137): "(i) the expansion rapidly converges; (ii) the polynomials have a simple form; and (iii) the polynomial approximates very closely the solution". In the present work, we have calculated seven Chebyshev polynomials 
of first kind $\left(T_{0}\right.$ to $\left.T_{6}\right)$, and the Eq. (17) was rewritten in the form

$$
\delta c=\sum_{i=1}^{I} \alpha_{i} T_{i-1}(x) \quad, \quad-1 \leq x \leq 1 .
$$

Then, the elements of the matrix $\boldsymbol{\Gamma}$ of Eq. (19) can be written as

$$
\Gamma_{m i}=R \int_{0}^{D}\left(\frac{\partial Q_{m}}{\partial \omega}\right) T_{i-1}(z) d z .
$$

Changing the limits of integration, from $[0, D]$ to $[-1,1]$ (the interval over which the set of Chebyshev polynomials is orthogonal), by change of variables

$$
x=\frac{2 z}{D}-1 \quad \Rightarrow \quad d x=\frac{2}{D} d z \quad \Rightarrow \quad d z=\frac{D}{2} d x
$$

the Eq. (22) can be written in the form

$$
\Gamma_{m i}=\frac{1}{2} R D \int_{-1}^{1}\left(\frac{\partial Q_{m}}{\partial \omega}\right) T_{i-1}(x) d x .
$$

\section{Inversion with Unsynchronized Arrivals}

The concept of OAT was developed to monitor the changes in the marine environment by using acoustic inverse techniques. The original idea was based on measuring perturbations in travel time between acoustic sources and receivers. This assumes very accurate source-to-receiver clock synchronization (Aulanier et al., 2013). In the ideal case, as illustrated in Figure $2, \boldsymbol{\delta} \boldsymbol{t}$ can be obtained by

$$
\delta t=t^{\text {real }}-t^{\text {model }}
$$

where vector $\boldsymbol{t}^{\text {real }}$ represents the set of times related to the maxima of the arrival pattern (recorded data), and vector $\boldsymbol{t}^{\text {model }}$, the set of arrival times calculated by Ray Tracing Model.

For the case of unsynchronized arrivals, the inversion should be performed based on relative arrival times (Rodríguez, 2000, p. 54), being necessary to rewrite Eqs. (19) and (20), and express $\boldsymbol{\Gamma}$ and $\boldsymbol{\delta} \boldsymbol{t}$ with a reduced number of lines (Rodríguez \& Jesus, 2004). Then, we must define the vector

$$
\Delta t=\Delta t^{\text {real }}-\Delta t^{\text {model }}
$$

where the vectors $\Delta t^{\text {real }}$ and $\Delta t^{\text {model }}$, as illustrated in Fig- ures 3 and 4 , corresponds, respectively, to

$$
\Delta \boldsymbol{t}^{\text {real }}=\left\{\begin{array}{c}
\Delta t_{2}^{\text {real }}=t_{2}^{\text {real }}-t_{1}^{\text {real }} \\
\Delta t_{3}^{\text {real }}=t_{3}^{\text {real }}-t_{1}^{\text {real }} \\
\vdots
\end{array}\right.
$$

and

$$
\Delta \boldsymbol{t}^{\text {model }}=\left\{\begin{array}{c}
\Delta t_{2}^{\text {model }}=t_{2}^{\text {model }}-t_{1}^{\text {model }} \\
\Delta t_{3}^{\text {model }}=t_{3}^{\text {model }}-t_{1}^{\text {model }} \\
\vdots
\end{array} .\right.
$$

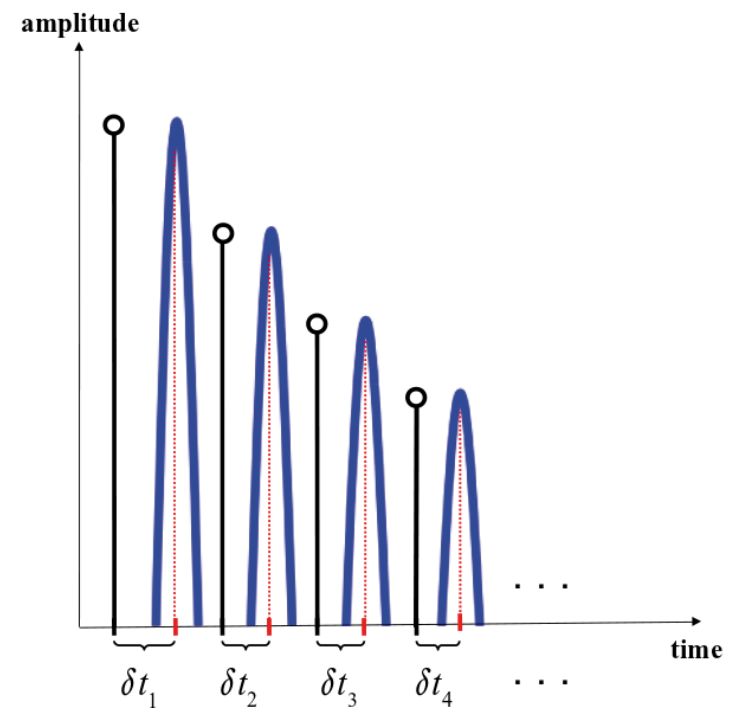

Figure 2 - Ideal Case: travel time differences between times related to the maxima of the arrival pattern (blue line) and times calculated by model (black stems).

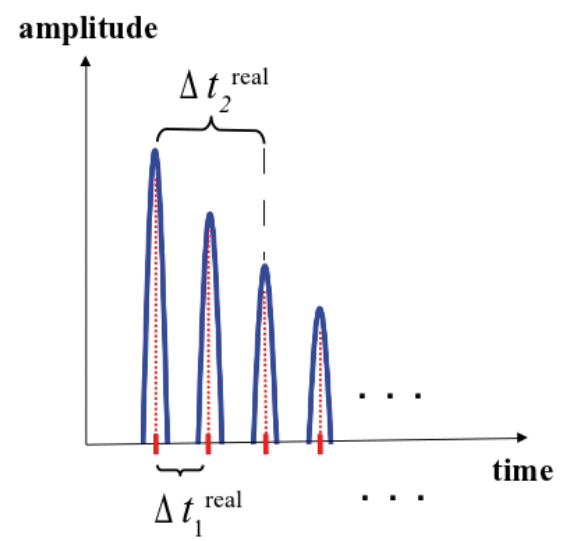

Figure 3 - Time differences (arrival pattern).

Then, considering the matrix $\boldsymbol{\Gamma}$ expressed as a new matrix $\boldsymbol{\Psi}$, 
and based on the definition of $\boldsymbol{\Delta} \boldsymbol{t}$, we can show that

$$
\begin{aligned}
\Delta t_{1} & =\Delta t_{2}^{\text {real }}-\Delta t_{2}^{\text {model }} \\
& =\left(t_{2}^{\text {real }}-t_{1}^{\text {real }}\right)-\left(t_{2}^{\text {model }}-t_{1}^{\text {model }}\right) \\
& =\left(t_{2}^{\text {real }}-t_{2}^{\text {model }}\right)-\left(t_{1}^{\text {real }}-t_{1}^{\text {model }}\right) \\
& =\boldsymbol{\Gamma}_{\mathbf{2}} \boldsymbol{\alpha}-\boldsymbol{\Gamma}_{\mathbf{1}} \boldsymbol{\alpha} \\
& =\left(\boldsymbol{\Gamma}_{\mathbf{2}}-\boldsymbol{\Gamma}_{\mathbf{1}}\right) \boldsymbol{\alpha}=\boldsymbol{\Psi}_{\mathbf{1}} \boldsymbol{\alpha} \\
& =\sum_{i=1}^{I}\left(\Gamma_{2 i}-\Gamma_{1 i}\right) \alpha_{i},
\end{aligned}
$$

with vectors $\boldsymbol{\Gamma}_{1}$ and $\boldsymbol{\Gamma}_{2}$ corresponding, respectively, to the first and the second row of matrix $\boldsymbol{\Gamma}$, and vector $\boldsymbol{\Psi}_{\mathbf{1}}$, to the first row of matrix $\boldsymbol{\Psi}$. So, the Eq. (19) should be rewritten in the form

$$
\Psi \alpha=\Delta t
$$

with least squares solution $(L<M)$ given by

$$
\alpha=\left(\Psi^{\mathrm{T}} \Psi\right)^{-1} \Psi^{\mathrm{T}} \Delta t .
$$

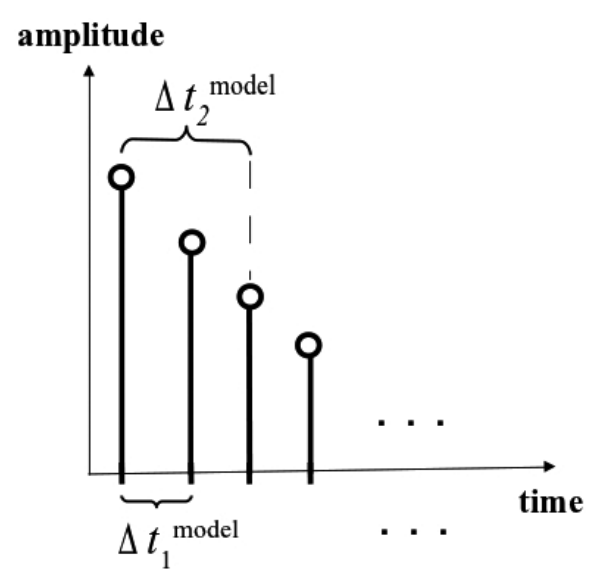

Figure 4 - Time differences (model).

\section{Array Processing}

In contrast with Matched Field Techniques, which deal in a natural way with array processing, the methods of Travel Time Tomography deal with the information acquired on a single hydrophone (Rodríguez, 2000, p. 87). The Eq. (30) results from the consideration of a single hydrophone. Considering $N$ sensors, we can get a set of matrix equations of the form

$$
\Psi_{1} \alpha=\Delta t_{1}, \Psi_{2} \alpha=\Delta t_{2}, \ldots, \Psi_{N} \alpha=\Delta t_{N}
$$

sharing the same vector $\boldsymbol{\alpha}$. Then, these equations can be reduced to a single set, identical to Eq. (30), as a concatenated system

$$
\boldsymbol{\Psi}=\left[\begin{array}{c}
\Psi_{1} \\
\Psi_{2} \\
\vdots \\
\Psi_{N}
\end{array}\right] \quad ; \quad \boldsymbol{\Delta} t=\left[\begin{array}{c}
\Delta t_{1} \\
\Delta t_{2} \\
\vdots \\
\Delta t_{N}
\end{array}\right]
$$

\section{SIMULATION}

The discretization sometimes becomes inappropriate to solve the IP. To illustrate this point, it was performed a modal inversion simulation, using sound speed based on CTD data, collected in the ITIMATE96 experiment. This experiment was carried out in June 1996, in the Nazaré site, on the continental shelf, 50 nautical miles north of Lisbon (Rodríguez et al., 2000, p. 6). It was considered a $\mathrm{RI}$ shallow water environment with depth of $135 \mathrm{~m}$, a source with frequency of $550 \mathrm{~Hz}$ and a receiver located at a distance of 5600 $\mathrm{m}$ from the source, according to Figure 5. Also, it was considered the propagation of normal modes only in the water column (trapped modes).

The reference Sound Speed Profile (SSP), $c_{0}(z)$, was the mean SSP, i.e., the average of 20 profiles collected on 14 June, 1996, as shown in the Figure 6 . The perturbed profile $c(z)$ was the first of these 20 profiles.

Fifty trapped normal modes were calculated for each profile, and the same number of modes becomes possible relate them one to one. The modes for $c_{0}(z)$ are not too different from the modes for $c(z)$. Then, it was possible to expect the simulation work properly. The Figure 7 shows the result obtained by modal inversion with discretization, but without parameterization. This result is bad, with very low accuracy, indicating that the approach used is very weak, by reason of discretization error. This fact shows that the set of sound speed perturbations must be discretized as a linear combination of basis functions, like is done in the parameterization.

Adopting the parameterization to fix the problem of accuracy, we got the result of Figure 8. As we can see, the inverted sound speed perturbation is close to the expected, showing a much better result. The parameterization of sound speed perturbations, using the Chebyshev polynomials, allowed to obtain a high accuracy result, showing the importance of parameterization and properties of polynomials.

\section{CONCLUSION}

The decision of how to discretize the set of model parameters is essential for an accurate inversion of the sound speed per- 


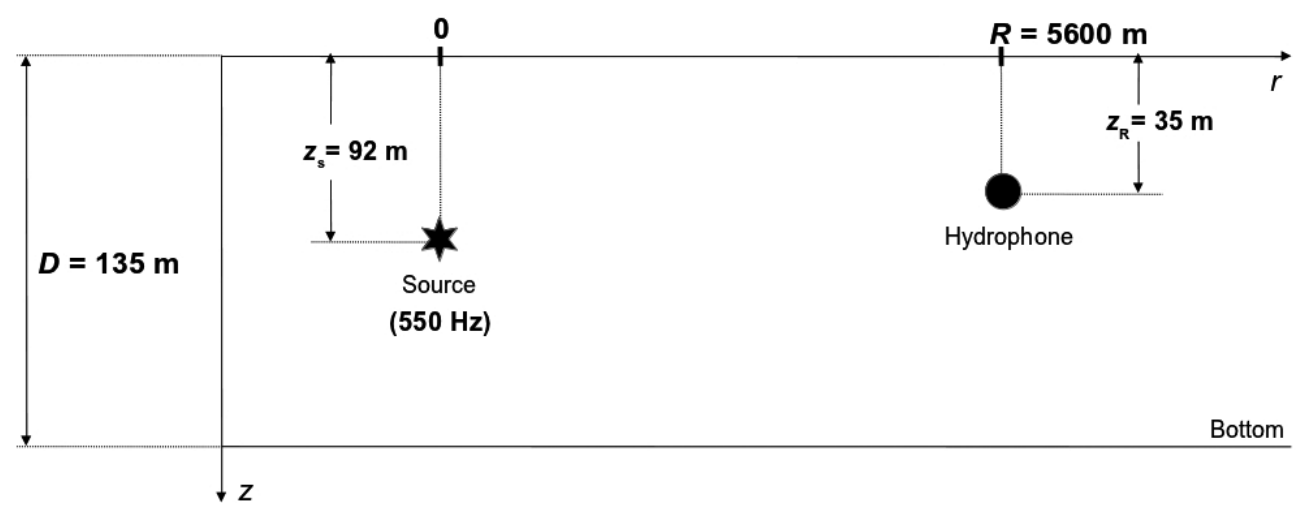

Figure $\mathbf{5}$ - RI shallow water environment, indicating some parameters that have been used in the modal inversion simulation.

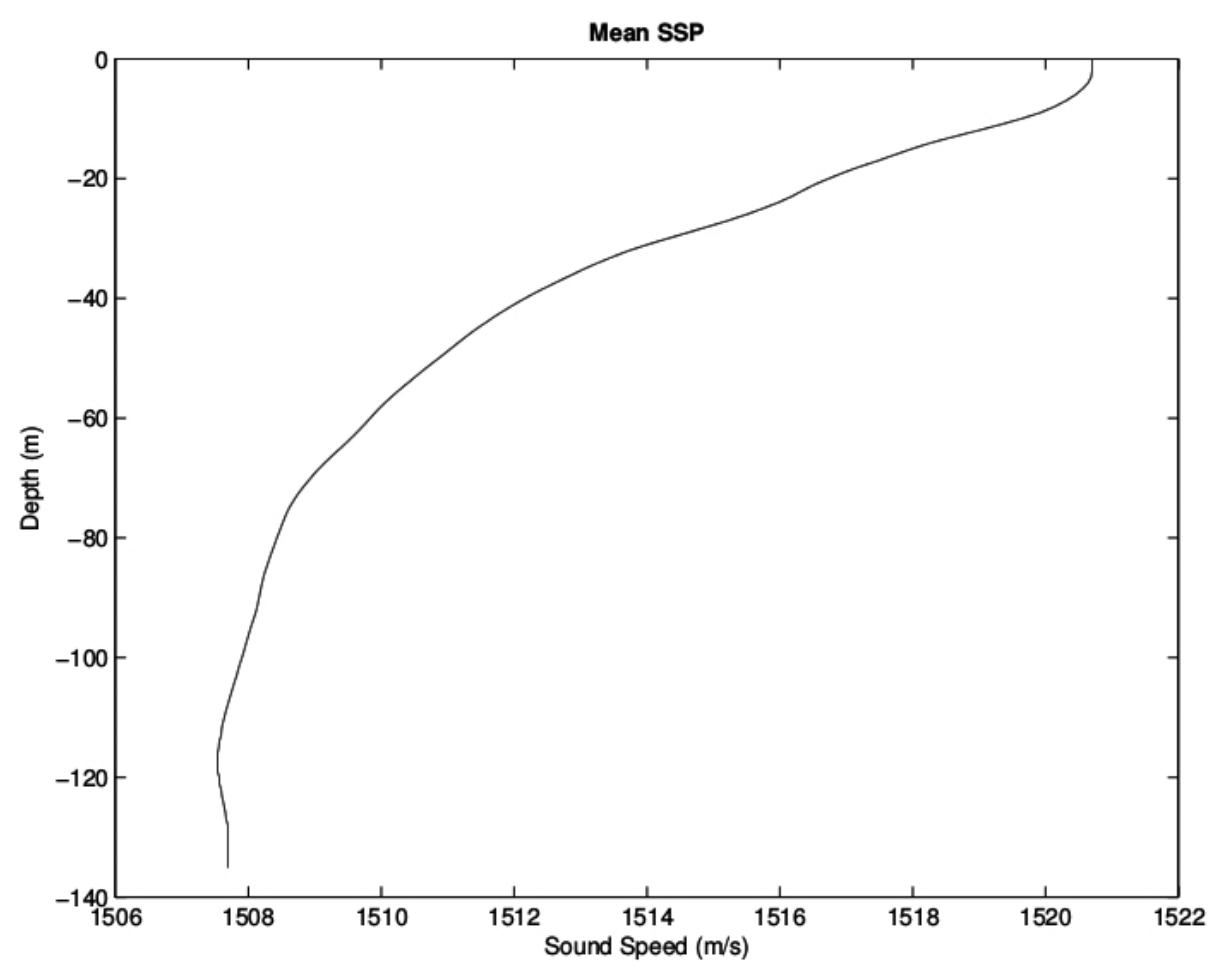

Figure 6 - INTIMATE96 (14 June): mean sound speed profile $(\mathrm{m} / \mathrm{s})$.

turbation. The representation of the set of unknowns by a linear combination of orthogonal functions reduces the degrees of freedom of the PI solution in a controlled way, with the advantage of $\|\boldsymbol{\alpha}\|_{2}=\|\boldsymbol{\delta} \boldsymbol{c}\|_{2}$. The choice of basis functions requires an adequate knowledge of the problem as well as the behavior of the basis. It was verified the efficiency of Chebyshev polynomials as orthogonal basis functions, to represent the sound speed perturbation. The formulation presented, after due adjustment matrix, could be used in the case of unsynchronized arrival. The resulting equation also can be used in the case of sensor array.

\section{ACKNOWLEDGEMENTS}

The authors are grateful to the SiPLAB (University of Algarve), for the kindly provided computational resources and facilities.

\section{REFERENCES}

AULANIER F, NICOLAS B \& MARS JI, ROUX P \& BROSSIER R. 2013. Shallow-water Acoustic Tomography from Angle Measurements Instead of Travel-Time Measurements. J. Acoust. Soc. Am., 134(4): EL373EL379.

CHIU C-S, MILLER JH \& LYNCH JF. 1996. Forward Coupled-Mode 


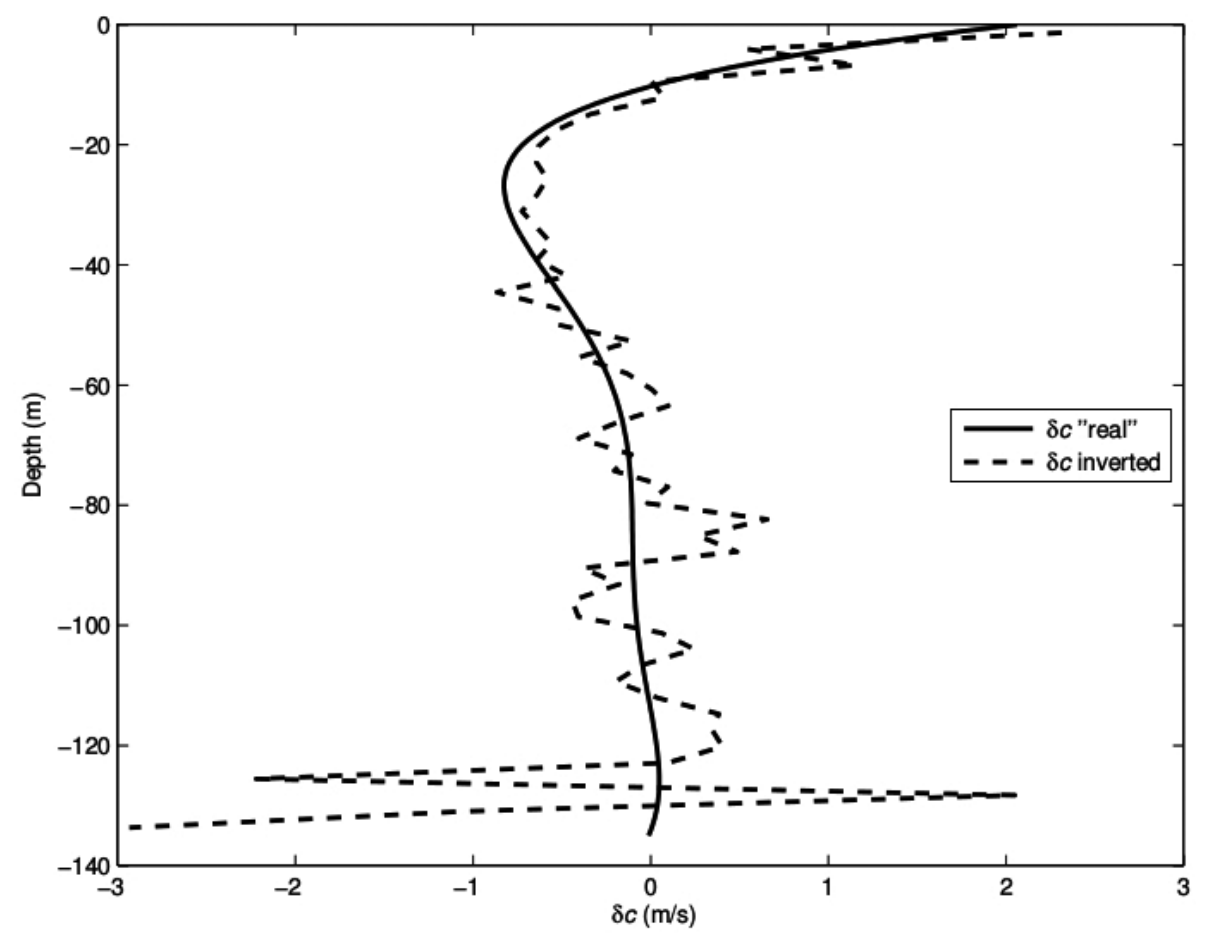

Figure 7 - Modal inversion with discretization (without parameterization). Solid line: $\delta c$ expected. Dashed line: $\delta c$ inverted.

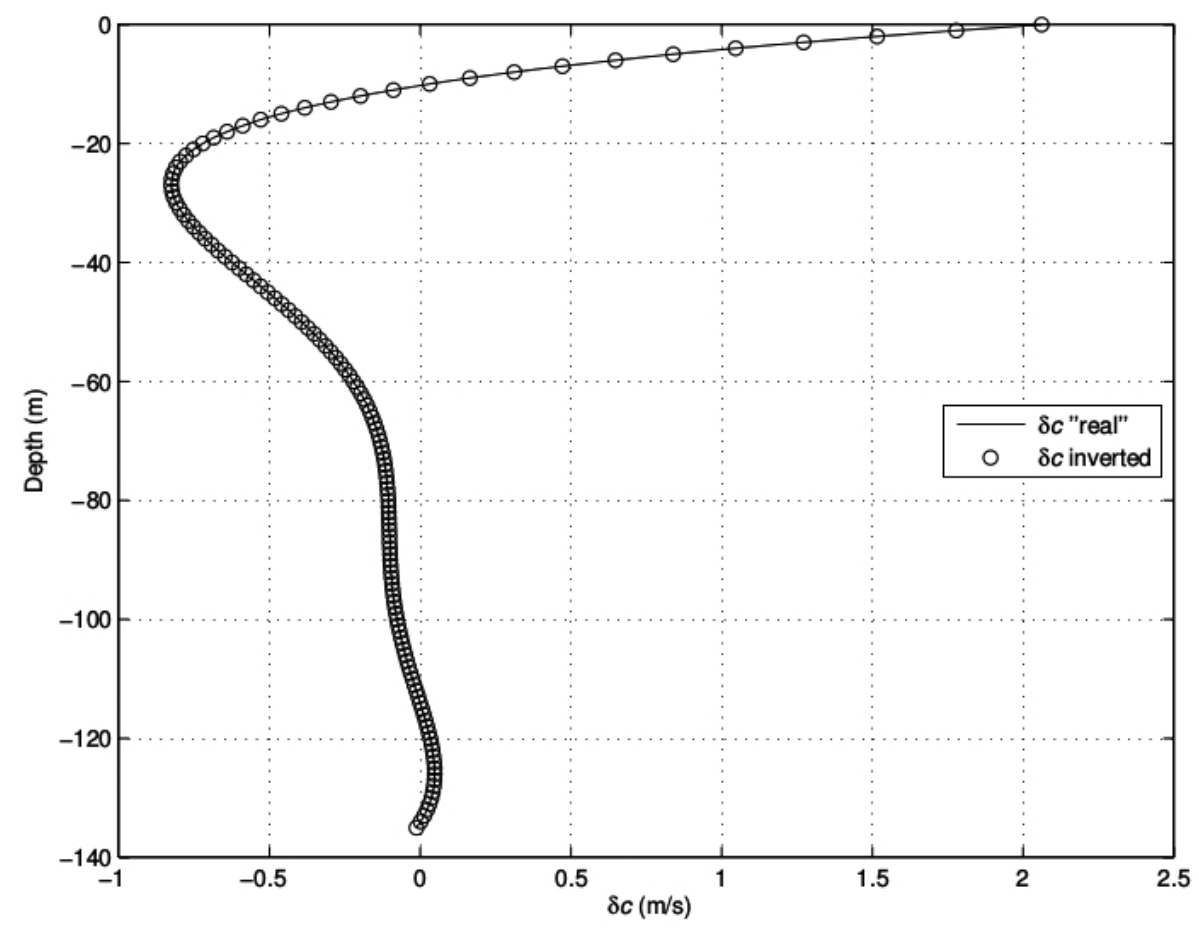

Figure 8 - Modal inversion with parameterization. Solid line: $\delta c$ expected. Circles: $\delta c$ inverted. 
Propagation Modeling for Coastal Acoustic Tomography. J. Acoust. Soc. Am., 99(2): 793-802.

RODRÍGUEZ OC. 2000. Tomografia Acústica Oceanográfica com Vista à Estimação de Marés Internas na Plataforma Continental. Doctorate Thesis, Universidade do Algarve, Faro, Portugal. xviii, 125 pp.

RODRÍGUEZ OC \& JESUS SM. 2000. Physical Limitations of Traveltime-based Shallow Water Tomography. J. Acoust. Soc. Am., 108(6): 2816-2822.

RODRÍGUEZ OC \& JESUS SM. 2002. Range-dependent Regularization of Travel Time Tomography based on Theoretical Modes. In: Proceedings of the Sixth European Conference on Underwater Acoustics, 88: 760-762, Gdansk, Poland, June.

RODRÍGUEZ OC \& JESUS SM. 2004. Range Dependent Tomography of Internal Tides with Relative Arrivals. In: Proceedings of the 2004 International Conference on Computational \& Experimental Engineering \& Science, p. 1747-1752, Madeira, Portugal, 26-29 July.

RODRÍGUEZ OC, JESUS SM, STEPHAN Y, DEMOULIN X, PORTER MB
\& COELHO E. 1998. Internal Tide Acoustic Tomography: Reliability of the Normal Modes Expansionas a Possible Basis for Solving the Inverse Problem. In: Proceedings of the Fourth European Conference on Underwater Acoustics, p. 587-592, Rome, Italy, 21-25 Sept.

RODRÍGUEZ OC, JESUS SM, STEPHAN Y, DEMOULIN X, PORTER MB \& COELHO E. 2000. Dynamics of Acoustic Propagation through a Soliton Wave Packet: Observations from the INTIMATE'96 Experiment. In: CAITI A, HERMAND J-P, JESUS SM \& PORTER MB (Eds.). Experimental Acoustic Inversion Methods for Exploration of the Shallow Water Environment. Dordrecht, The Netherlands, Kluwer Academic. p. 1-18.

SCHULTZ DR \& STRAYER MR. 2005. Computational Techniques. In: DRAKE GWF (Ed.). Springer Handbook of Atomic, Molecular, and Optical Physics. 2nd ed., cap. 8, Springer. p. 135-152.

TAROUDAKIS MI. 1994. Variations of Tomography Signals in Shallow Water due to Bottom Topography Irregularities. Journal de Physique, 4 : C51079-C51082. 